\title{
Time-course Pattern of Carrot Storage Root Growth in a Solid Substrate, Sub-irrigation Culture System
}

\author{
Toshihiko Eguchi', Takehiko SuzUkI ${ }^{2}$, Satoshi YoshidA ${ }^{1}$, Ikuo MiYaJima ${ }^{3}$ \\ and Masaharu KITANO ${ }^{4}$ \\ 'Biotron Application Center, Kyushu University, Fukuoka 812-8581, Japan \\ ${ }^{2}$ Japan Tobacco Inc, Tokyo 105-8422, Japan \\ ${ }^{3}$ Institute of Tropical Agriculture, Kyushu University, Fukuoka 812-8581, Japan \\ ${ }^{4}$ Applied Meteorology Laboratory, Department of Bioproduction Environmental Science Graduate \\ School of Bioresource and Bioenvironmental Sciences, Kyushu University, Fukuoka 812-8581, Japan
}

(Received August 26, 2011; Accepted October 12, 2011)

\begin{abstract}
A fast-maturing carrot cultivar that produces small storage roots termed "mini carrot" was grown in a solid substrate, sub-irrigation culture system placed in a phytotron glass room with a controlled air temperature of $23^{\circ} \mathrm{C}$ and relative humidity of $70 \%$. Patterns of storage root growth and accumulation of chemical compounds in the roots were investigated. Optimal time for harvest determined by the root size was limited to 1 week-between 9 and 10 weeks after seeding. Fresh weight of the storage root increased by the greatest amount between 8 and 9 weeks after seeding. However, increase in length, diameter, and fresh weight of the storage roots reached a plateau at 11 weeks after seeding. The increase in $\beta$-carotene and sucrose content was slow until 9 weeks after seeding - just before the optimal harvest time. Thereafter, accumulation of these nutrients became more active, and their contents increased by approximately 2 -fold at 3 weeks after the optimal harvest time.
\end{abstract}

Keywords : carrot, growth, nutrient accumulation, storage root, time-course pattern

\section{INTRODUCTION}

Vegetable production in a "plant factory" system — an advanced plant production system using a closed growing facility - is gradually spreading in Japan. However, an improvement in the expertise to cultivate various vegetables including root and fruit vegetables, is required to expand economically viable, easy-to-grow vegetables for plant factory systems, since plant factories currently in operation are mainly limited to the production of leafy vegetables, which are easy to cultivate and harvested early. In general, compared with leafy vegetables, root vegetables require longer cultivation times, greater planting distance, and more root space. In carrot (Daucus carota L.) cultivars, the first-maturing cultivars are called "mini carrots" which form small storage roots, and it can be harvested following a relatively short growth period with high planting density and reduced volume of root media. The plant factory system commonly utilizes hydroponics for artificial control of optimal plant growing conditions. For mini carrot hydroponics, Eguchi et al. (2009) previously demonstrated that a solid substrate, sub-irrigation culture system is able to create stable water conditions in the root media, which are necessary for healthy growth of the carrot storage

Corresponding author: Toshihiko Eguchi, fax: $+81-92-642-3069$, e-mail : egut@agr.kyushu-u.ac.jp 


\section{T. EGUCHI ET AL.}

root (Kakehashi and Kuroshima, 1997).

With regard to the quality of carrot storage roots, many studies have been conducted on the sweetness and the bitterness of these roots, and it has been suggested that most consumers favor carrot with strong sweetness (Simon et al., 1980; Martens et al., 1983; Varming et al., 2004). Chemical and sensory parameters of the root, which determine taste, are greatly influenced by the climate (Rosenfeld et al., 2002). This implies that environmental control techniques should be used to control of the root quality. To obtain an optimized control program of the growing conditions for carrots, time course patterns of root growth and accumulation of chemical compounds such as sugars and pigments in the root must be first determined. In this study, we examined the time course of storage root growth of a fast-maturing carrot cultivar and also examined changes in the contents of chemical compounds in the root.

\section{MATERIALS AND METHODS}

\section{Plant materials}

The fast-maturing carrot cultivar 'Baby-carrot' (Sakata Seed Corp., Yokohama) that produces small and cylindrical storage root was employed. This cultivar has orange-colored roots, in which $\beta$-carotene is the major carotenoid (Surles et al., 2004).

\section{Cultivation method}

A solid substrate, sub-irrigation culture system was used for the cultivation of the mini-carrot cultivar (Fig. 1), which has been shown to retain stable water conditions in the root media (Eguchi et al., 2009). Two 1/5000 ares-Wagner pots (inner size: diameter, $158 \mathrm{~mm}$; height, $190 \mathrm{~mm}$ ) were installed in a plastic container (inner size: width, $250 \mathrm{~mm}$; length, $370 \mathrm{~mm}$; height, $145 \mathrm{~mm}$ ). Groundwater level in the root media was adjusted by controlling the level of nutrient solution within the plastic container. Groundwater level was set at $-15 \mathrm{~cm}$ from the root media surface. Undesirable growth of algae in the nutrient solution was inhibited by covering the solution surface with plastic balls. Silica sand (grain size: $0.2-1 \mathrm{~mm}$, porosity: $0.46 \mathrm{~m}^{3} \mathrm{~m}^{-3}$, Saitozaki Kosan, Fukuoka) was used for root media. Half-strength of a commercial nutrient solution (Otsuka Chemical Co., Ltd., Osaka) adjusted to pH6.0 was used, and the electrical conductivity was adjusted to within $1.22-1.26 \mathrm{mS} \mathrm{cm}^{-1}$.

The culture system was installed in a phytotron glass room, controlled at an air temperature of $23^{\circ} \mathrm{C}$ and a relative humidity of $70 \%$. Under the same cultural condition, the mean daily temperature of the root media was almost the same as the air temperature at any depth, although solar irradiance caused fluctuations of the media temperature (Eguchi et al., 2009). Carrot seeds were circularly sown in well-moistened root media on May 6,2009, and the media surface was covered

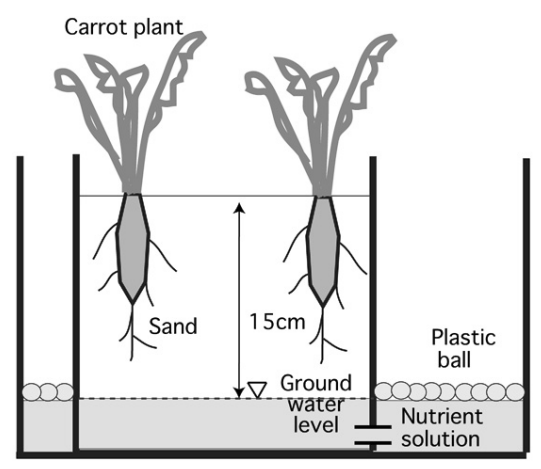

Fig. 1 Schematic diagram of carrot culture system. 


\section{STORAGE ROOT GROWTH OF MINI CARROT}

with a paper towel to avoid excess dryness. The paper towel was removed at 10 days after seeding, and plants were thinned-out 14 days after seeding to achieve 2 -cm intra-row spacing. Five plants were sampled at 6 weeks after seeding, and 6 plants were sampled at 7-11, and 13 weeks after seeding to investigate storage root growth and changes in the contents of chemical compounds in the root. The total amount of global radiation during the 13 weeks was about $1470 \mathrm{MJ} \mathrm{m}^{-2}(94 \%$ of the normal year) at the Fukuoka meteorological observatory nearest to the phytotron glass room.

Growth measurement of storage root

Storage root size and weight were investigated. Length and diameter of the storage root were measured with a caliper. For evaluation of the root shape, root diameters were measured along the root axis at $10-\mathrm{mm}$ intervals.

\section{Quantification of chemical compounds}

The content of sugars and $\beta$-carotene in the storage roots was investigated. Distribution of sugar contents is heterogeneous in the storage root; sucrose content is high in the basal part, while glucose and fructose are high in the distal part (Habegger et al., 1996; Rosenfeld, 2003). The sampled root was subsequently divided into 2 at the longitudinal axis, and each half was used for quantification of sugars and $\beta$-carotene.

Beta-carotene content in the storage root was quantified as this substance is the major pigment in the orange colored roots (Surles et al., 2004) and is also the principal factor that determines nutritional value. Extraction and quantification of $\beta$-carotene were carried out by the method reported by Mizda et al. (2002). Briefly, sampled storage roots were ground immediately, and $\beta$-carotene was extracted with acetone. The extract was analyzed with a gradient high-performance liquid chromatography (HPLC) system (pump, LC-10AD; column oven, CTO-10A; UV-VIS detector, SPD-10AV, SHIMADZU Corp, Kyoto).

The contents of sucrose, glucose, and fructose in dry matter content of the storage root are about $20-45 \%, 10 \%$, and $10 \%$, respectively (Nilsson, 1987), while contents of maltose, galactose, arabinose, and lactose were only about $0.5 \%$ of the dry matter content (Odebode and Unachukwu, 1997; Galindo et al., 2004). Starch content also constitutes about $0.9 \%$ of the dry matter (Svanberg et al., 1997). Accordingly, the contents of sucrose, glucose, and fructose were investigated in this study, and total sugar content in the root was calculated as the sum total. For quantification of the sugars, sampled roots were ground immediately and the juice squeezed. The volume of juice was subsequently diluted 5-fold with deionized water. The diluted juice was filtered through a membrane filter (DISMIIC-25AS; ADVANTEC MFS Inc., Tokyo), and sugar content in the filtrate was analyzed using an HPLC system (LC-10AD; SHIMADZU Corp., Kyoto). The filtrate was injected into the HPLC system, and the column was maintained at $40^{\circ} \mathrm{C}$ and eluted with water at a flow rate of $0.7 \mathrm{~mL} \mathrm{~min}{ }^{-1}$.

\section{RESULTS AND DISCUSSION}

\section{Storage root growth}

Figure 2 shows time-course changes in length, maximum diameter, and fresh weight of the carrot storage root. The increase in storage root length reached a plateau at 9 weeks after seeding (WAS), and the increase in width and fresh weight plateaued at 11 WAS. Storage root length showed the largest increase between 6 and 7 WAS, and thereafter the elongation became slow from 7 to 10 WAS. The maximum diameter linearly increased from 6 to 9 WAS and then the enlargement slowed during 9 to 11WAS. Although the fresh weight continued to increase from 6 to 11 WAS, the increase in the fresh weight was most active from 8 to 9 WAS. At 13 WAS, the thickening growth of the storage root appeared to cease. Cessation of storage root elongation preceding to the termination of the expansion is a growth pattern that is generally observed for carrots (Rubatzsky et al., 1999). 


\section{T. EGUCHI ET AL.}

In general, the optimal harvest time of carrots, i.e. the maturity of the storage root, cannot be judged by the appearance of the storage root (Fritz and Habben, 1975; Nilsson, 1987). The most important factors determining quality of the carrot cultivar used in this study are its size and form. The harvest time of the cultivar is generally judged by the size of the storage root, a length of approximately $100 \mathrm{~mm}$; maximum width, 15-20 mm; and form, cylindrical (Sakata Seed: private communication). In our experiment, storage roots grew to the appropriate length and width at 9 WAS, while the width became larger after $10 \mathrm{WAS}$ and exceeded the optimal size. As shown in Fig. 3, the storage root expanded entirely along the longitudinal axis until 10WAS, whereas only the basal part expanded after $10 \mathrm{WAS}$; this resulted in triangular pyramid shape. The most desired shape of the storage root in terms of market value is cylindrical; therefore, the shape of the storage root after 10 WAS may reduce the quality of its appearance. These results indicate that the optimal harvest time of the cultivar grown under the condition of this study is limited to 1 week-between 9 and 10 WAS. The storage root showed most active growth just before the harvest time.

Accumulation of chemical compounds

Figure 4 shows time-course change in the $\beta$-carotene content of the growing storage root.

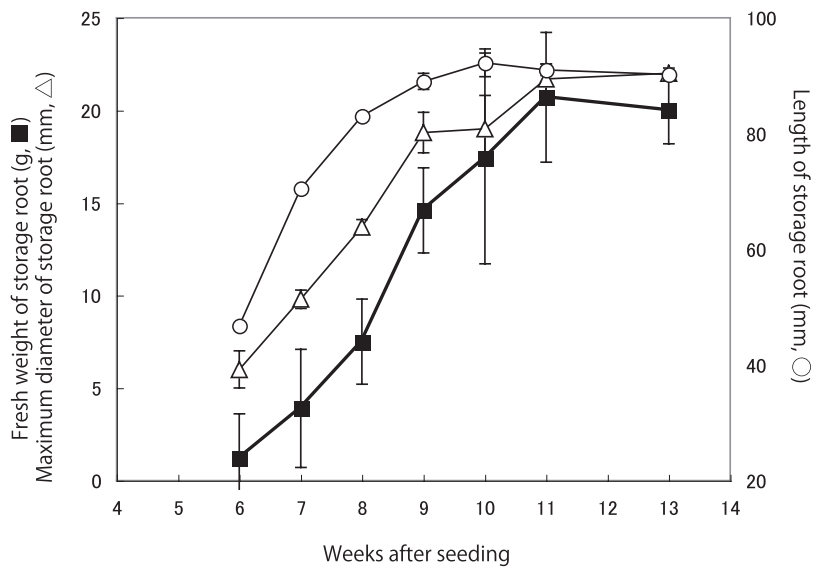

Fig. 2 Time-course changes in maximum diameter $(\triangle)$, length $(\square)$, and fresh weight $(\bigcirc)$ of carrot storage root grown in solid substrate culture system. Vertical bars indicate standard errors.

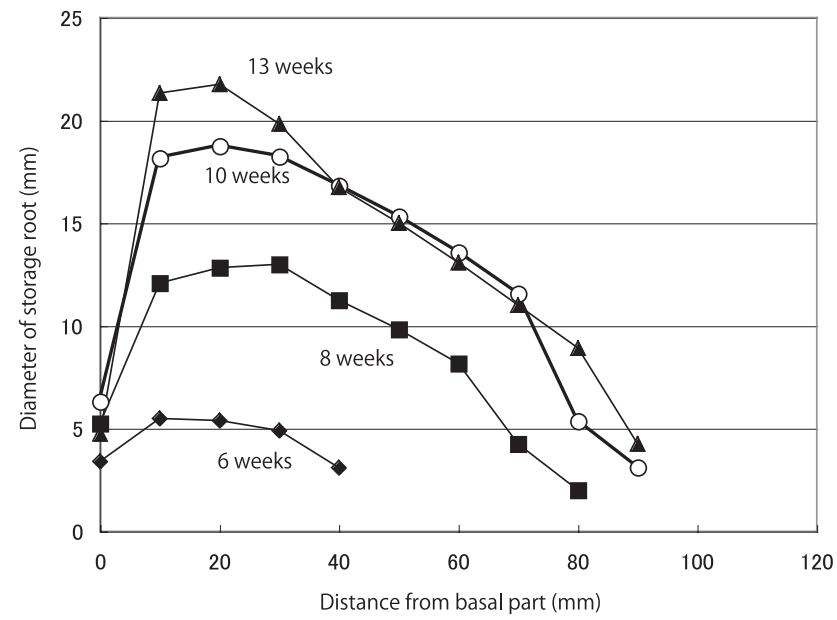

Fig. 3 Changes in shape of carrot storage root during cultivation in solid substrate culture system. 


\section{STORAGE ROOT GROWTH OF MINI CARROT}

Beta-carotene content continued to increase during the experimental period, and the increase after 9 WAS was larger than that between 7 and 9 WAS at which time the storage root did not attain the appropriate size for harvest. Active accumulation of $\beta$-carotene continued after the storage root exceeded the optimal size for harvest, since the content at 13 WAS was twice that at 9 WAS.

Figure 5 shows time-course changes in sugar contents of growing storage root. The content of glucose and fructose remained almost unchanged between 7 and 10 WAS, and appeared to slightly decrease thereafter. Sucrose content also scarcely changed from 7 to 9 WAS, while it displayed a increase at 9 WAS when the storage root grew to the appropriate size for harvest. Active sucrose accumulation was maintained until the end of the experiment. The sucrose content at 13 WAS further increased to 4- and 2-times the contents at 9 and 10 WAS, respectively. Percentage of sucrose to total sugar content was $49 \%$ at harvest time ( 9 WAS), $71 \%$ at $10 \mathrm{WAS}$, and $86 \%$ at 13 WAS. Thus, time-course changes in the total sugar content of the storage root of this cultivar were solely due to changes in the sucrose content as reported by Kjellenberg (2007) for other

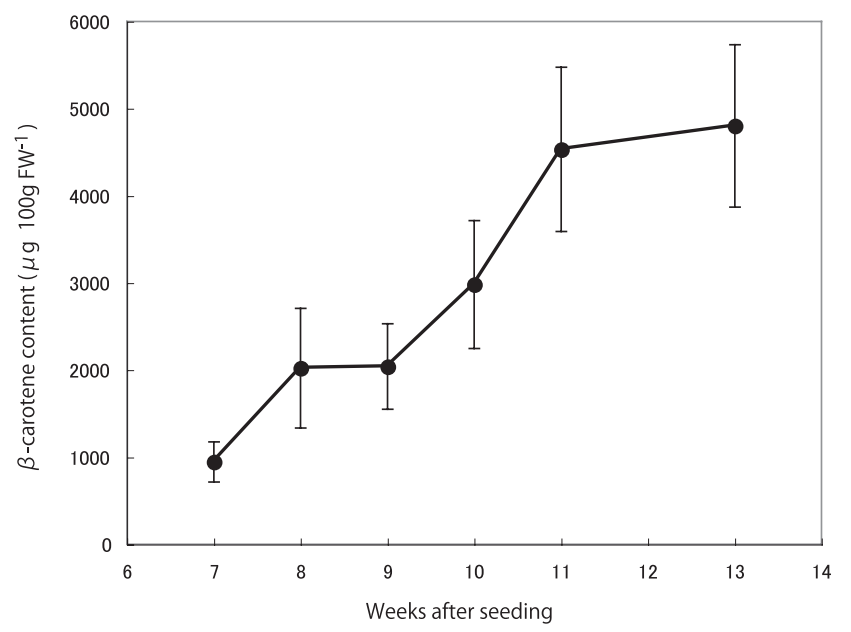

Fig. 4 Time-course of $\beta$-carotene content in carrot storage root. Vertical bars indicate standard errors.

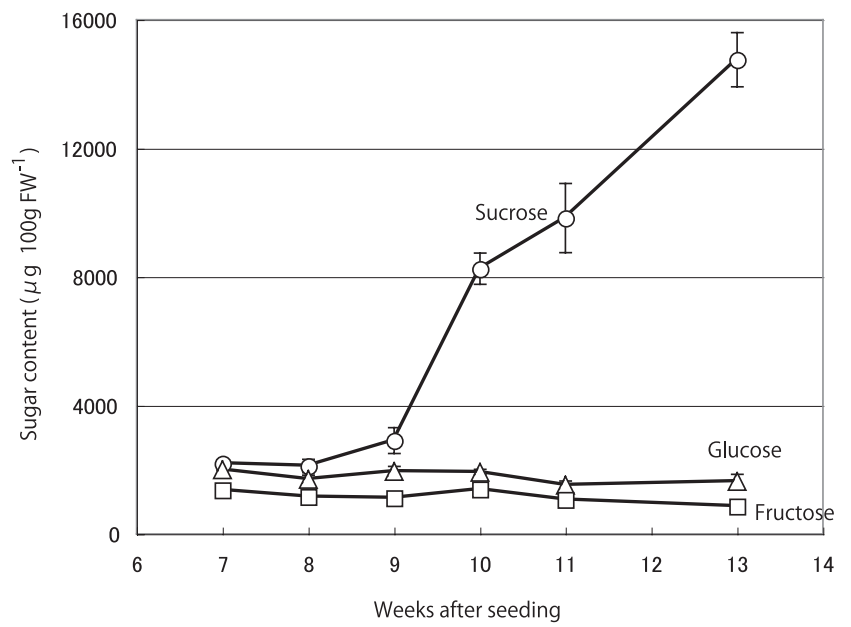

Fig. 5 Time-course of sugar (fructose, glucose, and sucrose) content in carrot storage root. Vertical bars indicate standard errors. 
cultivars.

During storage root development of the fast-maturing carrot cultivar 'Baby carrot', the content of glucose and fructose scarcely changed during the growth, although the content of $\beta$-carotene and sucrose showed large increase, particularly after 9 WAS at which time thickening growth of the root became inactive. At the optimal harvest time for this cultivar, which is determined by the size of the storage root, the storage root is still at the midpoint of growth with respect to commercial properties such as color, nutrition, or sweetness. Our results suggest that the cultivation methods aimed at increasing the sucrose and $\beta$-carotene contents at an earlier stage should be developed to improve productivity. Rosenfeld et al. (1998a, b) showed that growth temperature is the most important factor determining the sensory quality and chemical composition of the carrot storage root. On the other hand, the total amount of light during the cultivation can positively affect the root weight and size (Rosenfeld et al., 1998b), although variation in light condition do not affect assimilate partitioning between shoot and storage root (Hole and Sutherland, 1990). Both of those temperature and light are the ordinary controllable factors in horticultural production. Thus, environmental control techniques may be effectively used for the development of cultivation methods in order to activate accumulation of sucrose and $\beta$-carotene in earlier stage.

\section{REFERENCES}

Eguchi, T., Suzuki, T., Miyamoto, H., Hamakoga, M., Yoshida, S., Chikushi, J., Kitano, M. 2009. Influence of ground water level on carrot growth in solid substrate culture system. (Japanese text with English abstract) J.SHITA 21: $65^{-71 .}$

Fritz, D., Habben, H. 1975. Determination of ripeness of carrots (Daucus carota L.). Acta Hort. 52: 231-238.

Galindo, F. G., Bråthen, E., Knutsen, S. H., Sommarin, M., Gekas, W., Sjöholm, I. 2004. Changes in the carrot (Daucus carota L. cv. Nerac) cell wall during storage. Food Res. Int. 37: 225-232.

Habegger, R., Müller, B., Hanke, A., Schnitzler, W. H. 1996. Geruchsgebende Inhaltsstoffe im ätherischen Öl von verschiedenen Möhrensorten. Gartenbauwissenschaft 61: 225-229.

Hole, C. C., Sutherland, R. A. 1990. The effect of photon flux density and duration of the photosynthetic period on growth and dry matter distribution in carrot. Ann. Bot. 65: 63-69.

Kakehashi, Y., Kuroshima, T. 1997. Effects of soil moisture tension on the lateral stripes in carrot root. (Japanese text) Bull. Tokushima Agric. Res. Cent. 33: 25-30.

Kjellenberg, L. 2007. Sweet and bitter taste in organic carrot. Introductory Paper at the Faculty of Landscape Planning, Horticulture and Agricultural Science 2007: 2, Swedish University of Agricultural Sciences, Alnarp (Sweden).

Martens, M., Fjeldsenden, B., Russwurm, Jr. H. 1983. Relationship between sensory and chemical quality criteria for carrots studied by multivariate data analysis. In "Sensory Qualities in Foods and Beverages; Definitions, Measurment and Control" (ed. by Martens, H., Williams, A. A., Atkin, R. K.), Ellis Horwood Ltd., Chichester, pp 233-246.

Mizda, Y., Shinmoto, H., Kobori, M., Tsushida, T. 2002. Separation and quantification of carotenoids and chlorophylls in vegetables by high-performance liquid chromatography. (Japanese text with English abstract) Nippon Shokuhin Kagaku Kogaku Kaishi 49: 500-506.

Nilsson, T. 1987. Carbohydrate composition during long-term storage of carrots influenced by the time of harvest. J. Hortic. Sci. 62: 191-203.

Odebode, A. C., Unachukwu, N. E. 1997. Effect of storage environment on carrot rots and biochemical changes during storage. Zeitschrift Für Lebensmittel-Untersuchung Und Forschung 205: 277-281.

Rosenfeld, H. J. 2003. Sensory, Chemical and Morphological Changes in Carrots (Daucus Carota L.) as influenced by climatic Factors. Dr. Agric. Thesis. Agricultural University of Norway.

Rosenfeld, H. J., Aaby, K., Lea, P. 2002. Influence of temperature and plant density on sensory quality and volatile terpenoids of carrot (Daucus Carota L) root. J. Sci. Food Agric. 82: 1384-1390.

Rosenfeld, H. J., Samuelsen, R. T., Lea, P. 1998a. The effect of temperature on sensory quality, chemical composition and growth of carrots (Daucus carota). I. Constant diurnal temperature. J. Hortic. Sci. Biotech. 


\section{STORAGE ROOT GROWTH OF MINI CARROT}

73: $275-288$.

Rosenfeld, H. J., Samuelsen, R. T., Lea, P. 1998b. The effect of temperature on sensory quality, chemical composition and growth of carrots (Daucus carota). II. Constant diurnal temperatures under different seasonal light regimes. J. Hortic. Sci. Biotech. 73: 578-588.

Rubatzsky, V. E., Quiros, C. F., Simon, P. W. 1999. Carrots and related vegetable Umbelliferae. CABI Publishing, New York, pp 304

Simon, P. W., Peterson, C. E., Lindsay, R. C. 1980. Genetic and environmental influences on carrot flavor. J. Am. Soc. Hortic. Sci. 105: 416-420.

Surles, R. L., Weng, N., Simon, P. W., Tanumihardjo, S. A. 2004. Carotenoid profiles and consumer sensory evaluation of specialty carrots (Duccus carota, L.) of various colors. J. Agric. Food Chem. 52: 3417-3421.

Svanberg, S. J. M., Nyman, E. M. G. -L., Andersson, R., Nilsson, T. 1997. Effects of boiling and storage on dietary fiber and digestible carbohydrates in various cultivars of carrots. J. Sci. Food Agric. 73: 245-254.

Varming, C., Jensen, K., Möller, S., Brockhoff, P. B., Christiansen, T., Edelbos, M., Bjørn, G. K., Poll, L. 2004. Eating quality of raw carrots -correlations between flavour compounds, sensory profiling analysis and consumer liking test. Food Quality and Preference 15: 531-540. 